\title{
Nanocellulose in bio-based food packaging applications
}

\author{
Henriette M.C. Azeredo ${ }^{\mathrm{a}, *}$, Morsyleide F. Rosa ${ }^{\mathrm{a}}$, Luiz Henrique C. Mattoso ${ }^{\mathrm{b}}$ \\ a Embrapa Tropical Agroindustry, R. Dra. Sara Mesquita, 2270, Fortaleza, Ceará CEP 60511-110, Brazil \\ ${ }^{\mathrm{b}}$ LNNA, Embrapa Instrumentation, Rua XV de Novembro, 1452, São Carlos, São Paulo CEP 13560-970, Brazil
}

\section{A R T I C L E I N F O}

\section{Article history:}

Received 30 October 2015

Received in revised form 2 March 2016

Accepted 6 March 2016

Available online $\mathrm{xxx}$

\section{Keywords:}

Nanomaterials

Cellulose whiskers

Nanocomposites

Polysaccharides

\begin{abstract}
A B S T R A C T
Cellulose nanostructures have been widely studied as components of materials for a variety of applications including food packaging. They are usually incorporated as a reinforcement phase in nanocomposites (as cellulose nanocrystals or cellulose nanofibrils). In other cases, cellulose nanostructures have been used as matrices for films-bacterial cellulose (BC) deserving a special attention in this context, since it is produced as naturally nanostructured membranes, which may grow in a medium containing other biopolymers (producing bottom-up built bionanocomposites), be impregnated with other components, or be disintegrated into nanofibribils or even nanocrystals. This review summarizes findings and prospective applications of nanocellulose for bio-based materials to be used in food packaging (including active packaging).
\end{abstract}

(C) 2016 Elsevier B.V. All rights reserved.

\section{Introduction}

Most materials used for food packaging applications are still produced from fossil fuels, thus non-renewable and also practically non-biodegradable, representing a serious environmental problem. Efforts have been made to reduce packaging waste while keeping food stability and quality, including development of biobased materials from renewable sources. The global market for biodegradable polymers increased from 0.4 to 1.3 billion pounds between 2006 and 2013 (BCC Research, 2013). However, the use of bio-based materials for food packaging is still limited because of their usually poor physical properties. The incorporation of reinforcing structures such as nanocellulose to these materials may improve those properties.

Two main types of cellulose nanostructures may be obtained-cellulose nanocrystals (CNCs) and nanofibrils (CNFs). CNCs (or cellulose whiskers) are needlelike crystals measuring $4-25 \mathrm{~nm}$ in diameter and $100-1000 \mathrm{~nm}$ in length (Jonoobi et al., 2015), often produced by processes involving bleaching (especially for lignin-rich materials) and acid hydrolysis, which remove noncellulose and most amorphous cellulose leaving the crystalline regions (Xu et al., 2013). George et al. (2011) prepared BCNCs using cellulase as a cleaner and more ecofriendly method when compared to conventional acid hydrolysis; the enzyme-processed

\footnotetext{
* Corresponding author.

E-mail addresses: henriette.azeredo@embrapa.br, ette@mpc.com.br (H.M.C. Azeredo).
}

BCNCs presented improved thermal stability (degradation starting at $379^{\circ} \mathrm{C}$, against $184^{\circ} \mathrm{C}$ for acid-hydrolyzed BCNCs). CNFs, also known as cellulose microfibrils, are aggregations of elementary fibrils (made up of crystalline and amorphous parts) with micrometer length and $10-100 \mathrm{~nm}$ in diameter (Jonoobi et al., 2015), usually isolated by mechanical processes such as high pressure homogenization, grinding and refining (Wang et al., 2007). An additional kind of nanocellulose reinforcing material is microcrystalline cellulose (MCC), closely related to CNC. It is formed by bundles of nanocrystals together with some amorphous parts, obtained by acid degradation which removes part of the amorphous regions (Petersson and Oksman, 2006).

Cellulose nanostructures have been most usually applied as reinforcing phases, but they may also be used as matrices for a variety of materials including films for food packaging applications. In this case, bacterial cellulose (BC) is especially useful, because of its peculiar properties. BC is already produced as a nanomaterial by Gluconacetobacter species cultivated in a medium with carbon and nitrogen sources. Although chemically identical to plant cellulose, BC is produced as a bottom-up process, in which the bacteria synthesize cellulose and build up bundles of nanofibrils forming and assembly of nanosized ribbon-shaped fibrils with $70-80 \mathrm{~nm}$ in width (Pecoraro et al., 2008) producing a pellicle (membrane) with a water holding capacity of 60-700 times its dry weight (Chang et al., 2012). It is also free from hemicellulose and lignin, reducing purifying costs and environmental damages derived from using harsh chemicals (Duarte et al., 2015). BC may be used to form films in different ways (Fig. 1). Intact BC membranes may be impregnated with dispersions containing other polymers 


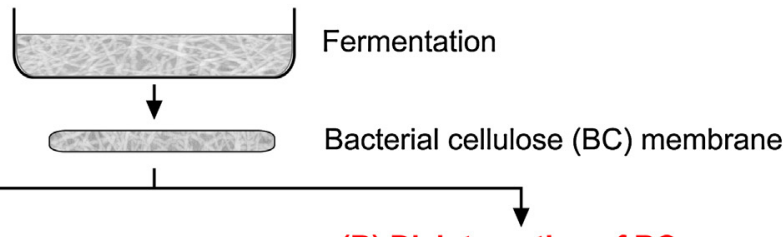

(A) Impregnation

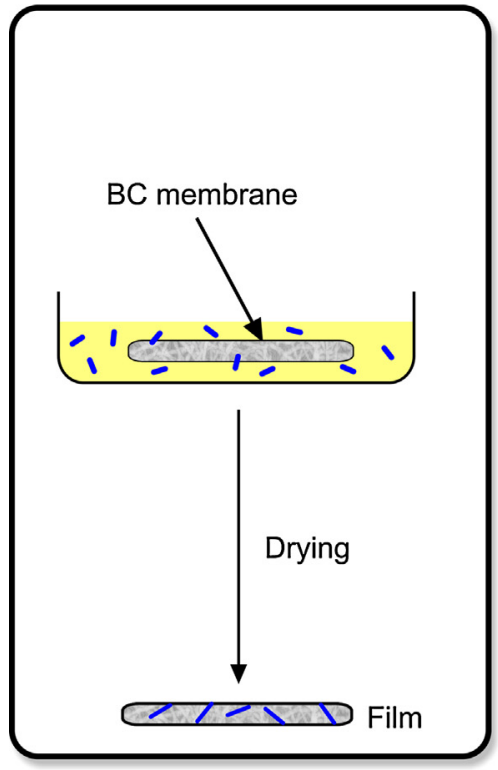

(B) Disintegration of $\mathrm{BC}$

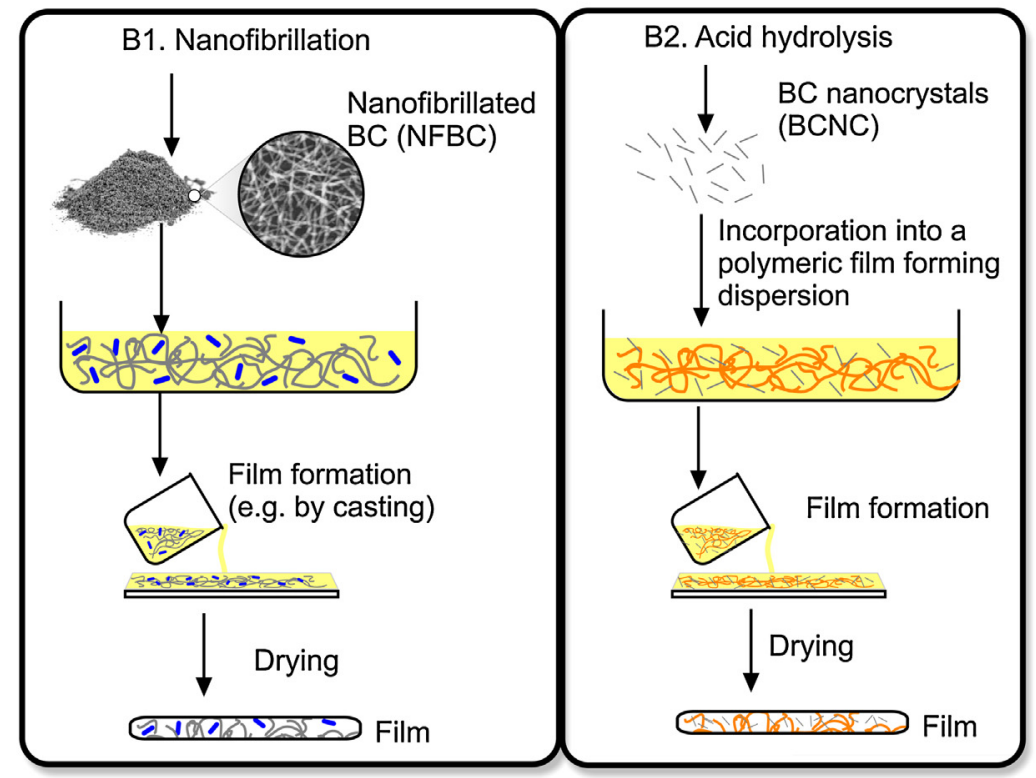

(C) Bottom-up built nanocomposites

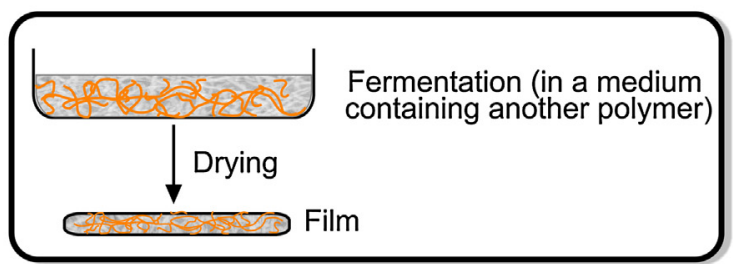

(1) Additional compounds (including polymers) to be incorporated

(2) Nanofibrillated cellulose (NFBC)

Bacterial cellulose nanocrystals (BCNC)

(2) Polymer (another than cellullose)

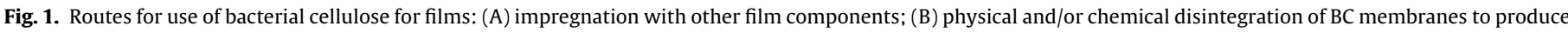
BCNF or BCNC; (C) addition of a second biopolymer to the culture medium for bottom-up built nanocomposites.

(Barud et al., 2011; Chang et al., 2012; Lin et al., 2013), reinforcing agents (Ul-Islam et al., 2012), and antimicrobials (Nguyen et al., 2008; Zhu et al., 2010). Also, a bottom-up technique may be used to self-assemble nanocomposites by growing $\mathrm{BC}$ in the presence of a second biopolymer added to the culture medium (Gea et al., 2010; Grande et al., 2009). However, a disadvantage in using intact BC sheets is the impossibility of changing their shape after fermentation, limiting applications such as coatings. Moreover, any changes in composition depend on either adding other components to the culture medium or impregnating membranes. For applications which require $\mathrm{BC}$ as a powder prior to formulation, sheets may be disintegrated by chemical and/or physical methods to produce bacterial cellulose nanofibrils (BCNF), or acid hydrolyzed to obtain bacterial cellulose nanocrystals (BCNCs) (George et al., 2011; George and Siddaramaiah, 2012).

Besides some basic requirements which are usually considered for most materials (e.g., tensile and thermal properties), food packaging materials should meet some specific requirements. The ultimate function of a food packaging is to extend food stability and to assure its quality/safety during shelf life. Barrier properties are especially important to reduce gases and water vapor exchanges between the food and the surrounding environment, decreasing the rates of chemical, physical, and microbiological changes. Water vapor permeability (WVP) and $\mathrm{O}_{2}$ permeability (OP) are then important attributes for materials intended for food protection. A decreased water solubility of hydrophilic materials is also important, since a certain degree of water resistance is desirable for most food applications, especially to avoid film disintegration when in contact with humid food surfaces such as meat and fresh-cut fruits. Transparency is also usually desirable, so the consumer can see the product.

The objective of this review is to summarize findings and applications of cellulose nanostructures for bio-based food packaging 
and coating purposes, focusing on the material properties related to food stability.

\section{Bionanocomposites with cellulose nanocrystals (CNCs)}

The most studied effects of CNCs on polymer matrices are on tensile properties. Those effects have been ascribed to the strength and stiffness of the CNCs (Cho and Park, 2011) as well as to a mechanical percolation effect yielded by CNC interactions by hydrogen bonding (Favier et al., 1995). The percolation theory predicts that enhancement in composite properties requires the presence of an amount of filler high enough to form a continuous structure, properly dispersed within the matrix (Ljungberg et al., 2005). Also, strength and modulus are typically increased by CNCs up to an "optimum" CNC content, usually around 5 wt\% (Abdollahi et al., 2013; Cho and Park, 2011; Huq et al., 2012; Khan et al., 2012), then impaired by higher CNC contents, which is usually ascribed to nanocrystal aggregation, and frequently followed by some loss of transparency (Abdollahi et al., 2013). CNC aggregation is frequently a problem, because of the hydrogen bonding interactions between $\mathrm{OH}$ groups on the surface of nanocrystals. In a study from our group (Santos et al., 2014), we found that sonication of gelatin-CNC-glycerol film forming dispersions significantly improved modulus, elongation, water vapor barrier, and transparency of the resulting films, indicating that the ultrasonic processing favored CNC dispersion.

Barrier improving effects of CNCs have also been reported, and ascribed to an increased path length for diffusing molecules by tortuosity effect (Dhar et al., 2015; Follain et al., 2013). Several authors reported that CNCs reduced WVP of a variety of matrices like alginate (Abdollahi et al., 2013; Huq et al., 2012), alginate-acerola puree (Azeredo et al., 2012b), chitosan (Khan et al., 2012), gelatin (George and Siddaramaiah, 2012), hydroxypropyl methylcellulose (HPMC) (George et al., 2014), poly(vinyl alcohol) (PVA) (Paralikar et al., 2008), and poly( $\varepsilon$-caprolactone) (PCL) (Follain et al., 2013). Some studies also reported CNCs to remarkably decrease OP of films (Dhar et al., 2015; Fortunati et al., 2012b; Li et al., 2013). CNC loadings as low as $2 \mathrm{wt} \%$ decreased the OP of poly (3-hydroxybutyrate) (PHB) films by about 65\% (Dhar et al., 2015).

The water sensitivity of hydrophilic films is another property which may be affected by CNCs. Although water vapor permeability and water sensitivity are both related to material hydrophilicity, they are different properties. Water vapor permeability refers to transport of water molecules through the film, whereas water sensitivity usually refers to the tendency of a film to have its own structure affected by water, usually by swelling or by dissolving. The effects of CNCs on water sensitivity of hydrophilic films have been determined by different tests such as water solubility (Abdollahi et al., 2013; Dhar et al., 2015), water sorption (George and Siddaramaiah, 2012; George et al., 2014), or water uptake (Chen et al., 2009; Dufresne et al., 2000; Khan et al., 2012; Li et al., 2009; Wang et al., 2006). Although CNCs are hydrophilic due to their $\mathrm{OH}$ groups, they have been proven effective to increase the water resistance of hydrophilic matrices such as alginate (Abdollahi et al., 2013), chitosan (Khan et al., 2012; Li et al., 2009), starch (Chen et al., 2009; Dufresne et al., 2000), gelatin (George and Siddaramaiah, 2012), soy protein isolate (Wang et al., 2006), and PHB (Dhar et al., 2015). This effect has been ascribed to the strong hydrogen bond interactions between $\mathrm{CNCs}$ and the matrix, improving the cohesiveness of the material (Abdollahi et al., 2013), and also to the high crystallinity of CNCs (Chen et al., 2009; De Paula et al., 2011).

CNCs have also been reported to improve thermal stability of biopolymers such as alginate (Huq et al., 2012) and PLA (Oksman et al., 2006; Petersson et al., 2007), whereas their effects on glass transition temperature $\left(\mathrm{T}_{\mathrm{g}}\right)$ of nanocomposites have been disputed-sometimes increasing $T_{g}$ (Alemdar and Sain,
2008; Anglès and Dufresne, 2000), sometimes presenting negligible effects on it (Martínez-Sanz et al., 2013a; Sanchez-Garcia and Lagaron, 2010). The $\mathrm{T}_{\mathrm{g}}$ of a starch-CNC nanocomposite plasticized with sorbitol increased with CNC contents up to 15\% (which was ascribed to the increased crystallinity, inducing physical crosslinks) and decreased above $15 \% \mathrm{CNC}$, which could be due to sorbitol ejection from the crystalline domains, increasing its concentration in the amorphous parts (Mathew and Dufresne, 2002).

George et al. (2011) used BCNC produced by cellulose action in nanocomposite PVA films, which exhibited better thermal properties than pure PVA. Also, the addition of $4 \mathrm{wt} \% \mathrm{BCNC}$ resulted in increased tensile strength and modulus (from 62.5 to $128 \mathrm{MPa}$, and from 2 to $3.4 \mathrm{GPa}$, respectively), when compared to pure PVA.

CNC from different sources usually present different properties, which may affect the metrices differently. Our group (Azeredo et al., 2012 b) studied the effects of CNCs from cotton fiber or coconut husk fiber (the latter submitted to one- or four-stage bleaching to remove lignin) on alginate-acerola puree films. The films with coconut CNCs were expected to present inferior tensile properties when compared to those of cotton CNCs, because of the hydrophobicity of the remaining lignin in coconut $\mathrm{CNCs}$ and its low compatibility with the polar matrix. However, films with coconut CNCs (despite of the bleaching harshness) presented similar tensile and water vapor properties to those of films with cotton CNCs, which was ascribed to a counterbalancing effect of the higher aspect ratios of coconut CNCs.

In a second part of the study (Azeredo et al., 2012a), CNC from coconut fiber and a montmorillonite nanoclay (MMT) were studied and compared as reinforcing agents in alginate-acerola puree films and coatings. The film forming dispersions were added with $10 \%$ CNC or MMT and used to form films and applied as coatings on fresh acerolas. Both nanocomposite films (with CNC and with MMT) presented similar WVP values, which were about $30 \%$ lower than that of the unfilled film, demonstrating the effectivity of the fillers in enhancing film barrier to water vapor. The performance of the different coatings was evaluated by comparing the properties of acerolas before and after 7 days of storage. The CNCcontaining coating decreased the fruit weight loss by $53 \%$, the decay incidence by $46 \%$, and the ascorbic acid loss by $70 \%$, when compared to uncoated acerolas. Also, the CNC- and MMT-containing coatings resulted in lower weight and ascorbic acid losses when compared to an unfilled alginate-acerola puree coating, suggesting that both CNC and MMT improved the overall barrier properties of the coating. When comparing the performance of CNC- and MMTcontaining coatings, the MMT coating provided a better fruit weight retention, while both coatings were comparable in terms of reducing decay incidence and retaining ascorbic acid.

An unusual plasticizer (limonene) was used by Fortunati et al. (2014) in bionanocomposite PLA films reinforced with CNCs ( 1 and $3 \mathrm{wt} \%$ ). The $\mathrm{CNC}$ addition resulted in increased elastic modulus (from 930 to $1050 \mathrm{MPa}$ ) without impairing film transparency, while limonene was effective as a plasticizer, increasing elongation of the $3 \%$ CNC film from $38 \%$ to $272 \%$. Considering that limonene is one of most important contributors to citrus flavor, the resulting material could be used for applications requiring (or benefiting from) citrus flavor-such as coatings for citrus fruits.

Emulsion bionanocomposite films were produced by Pereda et al. (2014) from chitosan, glycerol, and CNCs, with or without olive oil as the hydrophobic phase. Both CNC and olive oil contributed to enhance water resistance and water vapor barrier of the films. The combination of $3 \%$ CNC and $10 \%$ olive oil reduced WVP and water solubility by $55 \%$ and $62 \%$, respectively, while increasing elastic modulus by $78 \%$, when compared to the film without lipid or CNC. The opacity was surprisingly decreased by CNC contents of up to $7 \%$, which was attributed to CNC-glycerol interactions, 
leaving less free glycerol in the glycerol-rich phase on chitosanglycerol phase separation, thus favoring transparency.

Since CNCs present strong hydrogen bonding between one another, achieving an appropriate percolation network may be challenging (Dufresne, 2010). These hydrogen bondings may promote the formation of $\mathrm{CNC}$ aggregates within the polymer matrix but, on the other hand, they are important to develop the CNC network in the matrix (Mesquita et al., 2012). In order to obtain an adequate percolation network, it is necessary to disperse CNCs within the matrix and to maximize the CNC-polymer interfacial adhesion, while keeping the hydrogen bonding between CNCs (Dufresne, 2010; Mesquita et al., 2012). One of the possible strategies to improve the dispersion of nanocrystals in polymeric matrices is the use of surfactants, which have been reported as effective agents to cover CNC surfaces and avoid nanocrystal agglomeration, enhancing their dispersion on film matrices (Fortunati et al., 2012a). Moreover, they may favor compatibility between cellulose and a hydrophobic matrix; the hydrophilic head of a surfactant adsorbs on the cellulose surface whereas its hydrophobic tail solves in the matrix, avoiding cellulose aggregation by steric stabilization (Hubbe et al., 2008). Several studies include the use of an acid phosphate ester of ethoxylated nonylphenol as surfactant in order to enhance CNC dispersibility and compatibility with poly(lactic acid) (PLA) (Bondeson and Oksman, 2007; Fortunati et al., 2012a, 2012b). Fortunati et al. (2012b) added different contents of pristine and surfactant-modified CNCs to poly(lactic acid) (PLA) cast films. The surfactant enhanced CNC dispersion and interaction with PLA, and the consequent barrier properties of the films. A concentration of surfactant-modified CNC as low as $1 \mathrm{wt} \%$ promoted reductions of $34 \%$ and $26 \%$ in WVP and $\mathrm{OP}$, respectively. The overall migration levels of the nanocomposite films to polar and nonpolar food simulants were within the limits for food contact materials, but the specific migration of $\mathrm{CNC}$ was not assessed. A negative effect of the surfactant was observed by Bondeson and Oksman (2007), who reported some degradation of the PLA matrix resulting from the surfactant.

Another strategy to prepare composite materials without CNC aggregation consists in by covalently link CNCs with the polymer matrix. Bionanocomposite films were prepared by covalently linking CNCs and chitosan (Mesquita et al., 2012). CNCs were functionalized with methyl adipoyl chloride, and the reactive methyl ester end groups on CNC surface reacted with chitosan amino groups. The tensile strength of chitosan films was increased from about $45-110 \mathrm{MPa}$, and the modulus, from about 1.35-3.75 GPa by addition of $60 \%$ CNC. Moreover, the water uptake of the nanocomposite films was decreased when compared to neat chitosan.

Although MCC has been much less used as a reinforcing material when compared to $\mathrm{CNC}$, it has been used by our group as a reinforcing phase for mango puree-based films (Azeredo et al., 2009) and chitosan films (Azeredo et al., 2010), being effective to increase tensile strength and modulus and to decrease WVP of both kinds of films.

\section{Bionanocomposites with cellulose nanofibrils (CNFs)}

Most studies with CNF reinforcements have been mainly focused on tensile properties, although some studies have reported other effects, such as decreased swelling degree (Jipa et al., 2012a, 2012b), WVP and water solubility (Jipa et al., 2012b) of PVA films, and improved thermal stability of chitosan (Fernandes et al., 2010).

CNFs were used by Iwatake et al. (2008) to reinforce PLA sheets, by premixing CNF with PLA using acetone as solvent, and kneading the mixture with a rotary roller mixer after removing the solvent. A CNF content of 10 wt\% resulted in $40 \%$ and $25 \%$ increases of modulus and tensile strength, respectively, without reducing elongation.
Fernandes et al. (2010) observed noticeable CNF effects to strength and modulus of different chitosans, with maximum modulus increments ranging from $78 \%$ to $320 \%$ (for water-soluble low molecular weight chitosan, whose modulus surpassed $6.5 \mathrm{GPa}$ when added with $60 \%$ CNF). Remarkable effects of BCNF on tensile properties of starch films have also been described (Soykeabkaew et al., 2012). Maximum modulus (2.6 GPa) and strength (58 MPa) were achieved by addition of $50 \mathrm{wt} \% \mathrm{BCNF}$, corresponding to 106fold and 20-fold the values for pure starch/glycerol film. The incorporation of $20 \mathrm{wt} \% \mathrm{CNF}$ to xylan-rich hemicellulose films plasticized with $25 \mathrm{wt} \%$ sorbitol (Peng et al., 2011) increased film strength and modulus from $11.9 \mathrm{MPa}$ and $0.74 \mathrm{GPa}$, respectively, to $150 \mathrm{MPa}$ and $17.2 \mathrm{GPa}$.

CNFs were reported by López-Rubio et al. (2007) to act both as a conventional reinforcement (increasing strength and modulus) and as plasticizer in amylopectin films. While pristine amylopectin films required at least $38 \%$ glycerol, CNF addition resulted in films with reasonable elongation (2-7\%) without glycerol, which was ascribed to the CNF ability to retain moisture.

Different cellulose structures have different effects on matrices. From the aforementioned examples, it is noticeable that CNFs present optimum effects on tensile properties of biopolymers when present at higher weight contents when compared to CNCs. Some studies have directly compared effects of types of nanocellulose. Xu et al. (2013) reported that each type (CNF and CNC) presented specific advantages over the other on a polyethylene oxide matrix. CNFs led to better strength and modulus than CNCs, which was ascribed to the larger aspect ratio and fiber entanglement of CNFs. On the other hand, CNF entanglements and percolation resulted in higher fiber agglomeration, impairing elongation. Transparency was less affected by CNCs, because of their smaller sizes.

The effects of three types of nanocellulose-CNF, TEMPOoxidized CNF (CNF-T), and CNC - on HPMC films were compared by Bilbao-Sainz et al. (2011). CNF-T (and, to a lower extent, CNF) impaired tensile properties and water vapor barrier when present at $13 \mathrm{wt} \%$, while the same $\mathrm{CNC}$ content improved those properties. Moreover, $\mathrm{CNC}$ resulted in a smaller transparency loss $(6 \%$, in contrast to more than $30 \%$ for CNF and CNF-T at the same contents), favoring the applicability of the CNC-added films for most food packaging applications.

\section{Nanostructured cellulose based film matrices}

BC compressed-molded films with different porosities have been obtained by Retegi et al. (2010) under different pressures (10-100 MPa) at $70^{\circ} \mathrm{C}$ for $48 \mathrm{~h}$ during oven drying. The porosities ranged from 3.2\% (100 MPa-pressed film) to 13.6\% (10 MPa-pressed film). The pressure affected film tensile properties, mainly tensile strength (which increased from 87.5 to $182.5 \mathrm{MPa}$ by pressure changing from $10 \mathrm{MPa}$ to $100 \mathrm{MPa}$ ), which was ascribed to a structure densification, reducing interfibrillar space and increasing the occurrence of interfibrillar bonding zones.

Tomé et al. (2010) esterified bacterial cellulose (BC) membranes with hexanoyl chloride, in order to impart a hydrophobic character to their surface. The esterification (confirmed by FTIR spectra) impaired the thermal stability of $\mathrm{BC}$, but improved its moisture barrier, decreasing WVP by about 50\%. Moreover, the membrane permeabilities to $\mathrm{O}_{2}, \mathrm{CO}_{2}$, and $\mathrm{N}_{2}$ at $100 \% \mathrm{RH}$ were also decreased by esterification, since it reduced the water uptake by the membranes and its consequent increased fractional free volume and increased gas diffusivity.

BC-montmorillonite (BC-MMT) nanocomposites were prepared by Ul-Islam et al. (2012) by impregnating BC sheets with MMT suspensions at different concentrations ( $1 \%, 2 \%$, and $4 \%$, for BC-MMT1, BC-MMT2, and BC-MMT3, respectively) for $24 \mathrm{~h}$ at $150 \mathrm{rpm}$. MMT 
was adsorbed onto the sheet surface and also penetrated into the BC matrix. The MMT amounts incorporated into sheets were: $25.72 \%$ for BC-MMT1, 40.36\% for BC-MMT2, and $45.06 \%$ for BC-MMT3. The $\mathrm{BC}$ crystallinity was decreased from $63.22 \%$ (pure $\mathrm{BC}$ ) to about $50 \%$ (BC-MMT3). The tensile strength was increased from $151 \mathrm{MPa}$ (pure $\mathrm{BC}$ ) to up to $210 \mathrm{MPa}$ (BC-MMT2). The nanocomposites presented also improved thermal properties, with degradation temperatures increased from $232^{\circ} \mathrm{C}$ (pure BC) to up to $310^{\circ} \mathrm{C}$ (BC-MMT3).

Films from BCNCs were prepared by Martínez-Sanz et al. (2013b), but their barrier properties were highly impaired at $80 \%$ $\mathrm{RH}$ due to disruption of hydrogen bonds holding the nanocrystal network. The films were then coated with hydrophobic layers (formed either by electrospun PLA fibers or hydrophobic silanes). PLA coating was more effective than silane coating to protect $\mathrm{BCNC}$ from moisture, reducing WVP and OP by $70 \%$ and $97 \%$, respectively, at $80 \% \mathrm{RH}$.

Belbekhouche et al. (2011) prepared films by casting sisal CNCs or CNFs suspensions. CNF films presented lower water diffusion coefficients than CNC films, which could be due to the presence of residual lignin, extractives, and fatty acids at their surface. CNF films were about a thousand times less permeable to gases than CNC films, which was ascribed to a lower porosity and the possibility of entanglement of CNFs.

Nanocellulose matrices may be applied as coatings to conventional polymers. While biopolymers are still not meant to completely replace conventional polymers because of their higher cost and lower performance, the application of biodegradable coatings may allow reduction in thickness of plastic films, decreasing their environmental impacts. Li et al. (2013) applied $1.5 \mu \mathrm{m}$-thick $\mathrm{CNC}$ coatings on polymer substrates - i.e., polyethylene terephthalate (PET), oriented polypropylene (oPP), oriented polyamide (oPA), and cellophane - providing them with remarkable $\mathrm{O}_{2}$ barrier, while keeping high transparency (around 90\%). The OP of CNC coatings were variable because of different CNC-substrate interactions, oPA presenting the lowest $\mathrm{OP}\left(0.003 \mathrm{~cm}^{3} \mu \mathrm{m} \mathrm{m}^{-2} \mathrm{day}^{-1} \mathrm{kPa}^{-1}\right)$. On the other hand, the water contact angles of films decreased because of the polarity of the $\mathrm{OH}$ groups of $\mathrm{CNC}$, which might be undesirable for some applications.

Coating paper is also interesting to improve its poor barrier properties and water resistance. Lavoine et al. (2014b) coated papers with a successive number of CNF suspension layers. A CNF coating of $7 \mathrm{~g} \mathrm{~m}^{-2}$ reduced the air permeance of the paper in $70 \%$, and the tensile properties were also improved. Carboxymethylated CNF coatings were cast at different grammages on paper substrates by Aulin et al. (2010), increasing grammages (from 1 to $5 \mathrm{~g} / \mathrm{m}^{2}$ ) resulting in an almost $10^{4}$ fold decrease in OP, and remarkable increase in oil resistance.

\section{Bottom-up built nanocomposites from bacterial cellulose (BC)}

BC may be combined to another biopolymer by using a bottomup technique, in which BC nanofibrils are allowed to grow in the presence of the second biopolymer added to the culture medium, producing self-assembled bionanocomposites. In this case, BC could be considered as a co-matrix with the second biopolymer or as a reinforcing phase grown within the matrix.

Grande et al. (2009) growed BC in media containing starch (which was gelatinized in different stages). The membranes were hot pressed into sheets with a BC volume fraction higher than $90 \%$. $\mathrm{X}$-ray diffractograms and tensile properties of BC-starch nanocomposites were similar to those of pure $\mathrm{BC}$, indicating that $\mathrm{BC}$ formed a coherent network in presence of starch.

Gea et al. (2010) compared an in-situ process of growing $\mathrm{BC}$ in a medium containing a $5 \%$ PVA solution with a $\mathrm{BC}$ impregnation process with a 5\% PVA solution. The in-situ process, besides being more simple, resulted in almost no changes in the $\mathrm{BC}$ fibril arrangement, and the composite exhibited improved transparency and elongation when compared to pure $\mathrm{BC}$, while the strength and modulus were similar to those of pure BC. The improved ductility was ascribed to the partial interruption of hydrogen bonds within $\mathrm{BC}$ network. The impregnation process, on the other hand, affected the ribbon morphology of $\mathrm{BC}$, forming aggregates which resulted in remarkably reduced strength and stiffness of the films.

\section{Nanocomposites produced by impregnation of bacterial cellulose (BC)}

$\mathrm{BC} /$ poly(3-hydroxybutyrate) (PHB) composites with different PHB contents (25-90wt\%) were prepared by Barud et al. (2011) from $B C$ membranes impregnated with PHB-chloroform solutions. The BC nanofibrils involved PHB pellets precipitated inside the $\mathrm{BC}$ network. Better tensile properties were observed for composite membranes than for any of the isolated polymers, producing tensile strength and modulus as high as $144 \mathrm{MPa}$ and $15.5 \mathrm{GPa}$, respectively (with 25\% PHB), and elongation of up to $9.5 \%$ (with $75 \%$ PHB), due to good interfacial adhesion and strong interactions between $\mathrm{BC}$ and PHB chains. The resulting tensile strength and modulus values were about three and twelve times higher (respectively) than those for high density polyethylene (HDPE) films as reported by ASTM D882-00 (2000).

Lin et al. (2013) produced BC-chitosan films by impregnating BC in a chitosan solution. The elastic modulus of the BC-chitosan film was much higher (132 MPa) than that of pure BC (34 MPa), whereas the tensile strength and elongation of $\mathrm{BC}$-chitosan film were lower (10 MPa and $29 \%$, respectively) than those of BC (15 MPa and $32 \%$, respectively). Chitosan provided the films with antibacterial properties against Escherichia coli and Staphylococcus aureus.

Crosslinked $\mathrm{BC} /$ gelatin films were obtained by Chang et al. (2012) by impregnating BC sheets in gelatin solutions (at concentrations of $0.5-20 \%$ ) at $50{ }^{\circ} \mathrm{C}$ for 7 days, and immersing the composite membranes in protein crosslinking agents. The gelatin/BC dry weight ratio increased with increasing concentration of gelatin solution, until gelatin became the continuous phase (when gelatin solutions at $15 \%$ and $20 \%$ were used). Before crosslinking, gelatin entered the $\mathrm{BC}$ networks, occupying empty spaces. Crosslinking promoted the formation of an interpenetrating $\mathrm{BC} /$ gelatin network, whose tensile properties were improved at higher gelatin contents.

\section{Nanocelluloses in antimicrobial food packaging materials}

Active food packaging systems are those which not only passively protect food products, but includes also any functionality to actively enhance food quality or stability. The most common active packaging systems are those which release active compounds (such as antimicrobial agents) onto food surface (Azeredo, 2013).

Antimicrobial food packaging materials based on silver nanoparticles (AgNPs) have been widely studied, thanks to their broad antimicrobial spectrum, high temperature stability and good processability (Kumar and Münstedt, 2005) although the potential toxicity of AgNPs have still been disputed (Kim et al., 2010; Xiu et al., 2012). PLA films with CNCs (treated or not with surfactant) and AgNPs were produced by Fortunati et al. (2012a) using melt extrusion. The AgNP-containing films presented bactericidal effects against Gram-positive and Gram-negative bacteria, and the presence of surfactant favored the tensile properties. Overall migration tests (using polar and nonpolar food simulants) revealed migration 
levels within the limits for food packaging materials, but silver was easily released from the nanocomposites to ethanol 10\% (the polar simulant) when surfactant-treated CNCs were used, exceeding the specific migration limits allowed by legislation.

Nguyen et al. (2008) impregnated BC membranes with nisin solutions, and studied the effects of nisin concentration and impregnation time on the ability of films to control Listeria monocytogenes and total aerobic bacteria on the surface of vacuumpackaged frankfurters. Films produced from $6 \mathrm{~h}$ impregnation with a nisin solution at $2500 \mathrm{IU} \mathrm{mL}^{-1}$ resulted in decreases in L. monocytogenes and total aerobic bacterial counts of about $2 \log \mathrm{CFU} \mathrm{g}^{-1}$ and more than $3 \log \mathrm{CFU} \mathrm{g}^{-1}$, respectively, after 14 days of storage, when compared to control uncoated samples.

BC tubes impregnated with $\varepsilon$-polylysine $(\varepsilon$-PL) were tested as antibacterial sausage casings (Zhu et al., 2010). The $\varepsilon$-PL/BC composite casings, besides presenting good tensile and barrier properties, exhibited activities against several bacteria, extending shelf life of sausages. Moreover, antimicrobial properties against $S$. aureus were not significantly lost after autoclaving the casings at up to $121^{\circ} \mathrm{C}$ for $30 \mathrm{~min}$, suggesting a good heat stability of the casings.

Compression molded films for sliced ham were prepared by Salmieri et al. (2014) from PLA and CNCs added with nisin. Ham slices were inoculated with $10^{4} \mathrm{CFU} \mathrm{g}^{-1}$ of L. monocytogenes, each slice was placed between two films, and the product was packaged into high barrier packaging, vacuum-sealed, and stored for 14 days at $4{ }^{\circ} \mathrm{C}$. Nisin decreased the tensile strength of the films, but on the other hand it assured complete inhibition of L. monocytogenes growth from the third day of storage. Nisin was gradually released from the films, up to $21 \%$ at day 14 . Unfortunately, the study did not include PLA-nisin films without CNC, so it is not possible to assess any CNC effects on the antimicrobial efficacy of the system.

George et al. (2014) incorporated both CNCs and AgNPs to HPMC. Although the active properties of the films were not evaluated, the authors observed that AgNPs exhibited favorable effects on the matrix, favoring elongation while helping CNCs to increase tensile strength and modulus, and reducing moisture sorption. Those effects were ascribed to interactions of AgNPs with $\mathrm{OH}$ groups of HPMC (observed by FTIR) in a physical crosslinking.

Wheat gluten bionanocomposite coatings containing 7.5\% CNC and $0.6 \% \mathrm{TiO}_{2}$ were applied by El-Wakil et al. (2015) on unbleached kraft paper sheets. Three coating layers (resulting in a $10.7 \mu \mathrm{m}$ increase in paper thickness) caused enhancements of more than $50 \%$ in mechanical properties (breaking length and burst index), and resulted in at least $98.5 \%$ reduction in counts of inoculated microorganisms (Saccharomyces cerevisiae, E. coli, and S. aureus) after $2 \mathrm{~h}$ of exposure to UV light (to photoactivate $\mathrm{TiO}_{2}$ ).

Some studies describe functionalization of nanocellulose with active groups, in order to incorporate additional properties to the structures and the resulting materials. Dong et al. (2013) applied TEMPO oxidation to modify CNFs with carboxylate groups which strongly interacted with AgNPs. The presence of AgNPs reduced $\mathrm{CNF}$ coalescence in films, probably because the carboxylate-Ag binding limited water solvation and hydrogen bonding between adjacent CNFs. The functionalized CNFs presented antibacterial properties against both Gram-positive and Gram-negative bacteria, which could be exploited for active food packaging applications.

BCNFs were reported by Jipa et al. (2012b) to speed up the release of sorbic acid from PVA/BCNF/sorbic acid antimicrobial films. On the other hand, other studies have presented $\mathrm{CNF}$ as a delivery and controlled release agent (Lavoine et al., 2014a, b, c, d), due to their nanoporous network and/or to the formation of chemical interactions between CNF and loaded molecules (Lavoine et al., 2014a). Lavoine et al. (2014a) used a CNF coating on paper to release caffeine as a model hydrophilic active compound. Three treatments were compared, in which paper was: (a) impregnated with caffeine (control); (b) impregnated with caffeine, then coated with
CNF; or (c) coated with a caffeine/CNF mixture. The treatment (c) presented better results than (b), since the nanofibril network trapped caffeine, promoting a more controlled and gradual release, more promising for most potential applications in the food packaging field. In another study, the group (Lavoine et al., 2014c) evaluated the ability of CNF coatings to control release of the antibacterial chlorhexidine digluconate (CHX), using the same kinds of treatments-(a) CHX-impregnated paper, (b) CHXimpregnated and CNF-coated paper, and (c) CHX/CNF-coated paper-which retained their activities for 18, 30, and 45 days, respectively.

Controlled release systems based on paper coated with CNF and/or $\beta$-cyclodextrin (BCD) were developed by Lavoine et al. (2014e) to deliver CHX. The antibacterial (CHX) was mixed with a CNF suspension, a BCD solution or both, and applied as coatings onto paper. The combination of $\mathrm{BCD}$ and $\mathrm{CNF}$ presented a complementary action, CNF affecting the burst effect, and BCD controlling CHX release over time (thanks to its ability to form an inclusion complex with the active molecule). The use of $\mathrm{BCD}$ alone promoted a slow CHX delivery, whereas the $\mathrm{BCD} / \mathrm{CNF}$ combination was presented as being more suitable for rapid delivery. The $\mathrm{BCD} / \mathrm{CNF}$ combined action was exploited in another study by the group (Lavoine et al., 2014d) on controlled release of carvacrol. Carvacrol was included in $\mathrm{BCD}$ (previously grafted onto paper), and the paper substrate was coated with a CNF suspension. The BCD-grafted paper retained an antibacterial activity against Bacillus subtilis (in previously inoculated agar plates) for $14 \mathrm{~h}$, against $4 \mathrm{~h}$ for the control (non-grafted paper), and the CNF coating extended this activity for additional $2 \mathrm{~h}$.

\section{Final considerations}

Physical properties (especially tensile and permeability properties) of food packaging materials are important to assure that the packaged products are reasonably protected from external factors, and that the deteriorating changes are kept at low rates. There are no specific legislation for physical properties of materials intended for food packaging. The only conventional standard found in the literature is the requirement that the tensile strength of packaging films should be more than 3.5 MPa (Kim et al., 1995). In order to evaluate if a novel or modified material meets the requirements for other physical properties, it is recommended that the materials usually employed for those applications, such as LDPE (low density polyethylene), HDPE (high density polyethylene), PP (polypropylene), and PET (polyethylene terephthalate), are used as references for comparison purposes.

When a material is intended for food contact, there are also safety issues involved, since there is the possibility of migration of components to the food. A recent review by Huang et al. (2015) summarizes the efforts on migration assessment for nanocomposite materials in food packaging. In the case of edible materials (such as edible films and coatings), the issue is even more important, since the compounds present in the materials are intended to be directly ingested, so any components should be considered as food components (instead of food contact components). Although the properties and safety of bulk cellulose are well known, the nanosized counterparts must be evaluated in terms of any potential toxic effects, since their small dimensions may allow them to penetrate into cells and eventually remain in the system. Moreover, the occupational and environmental risks related to cellulose nanomaterials should be widely assessed as well. Some specific studies have indicated a low toxicity (Kovacs et al., 2010; Ni et al., 2012) and low environmental risks (Kovacs et al., 2010) of nanocellulose. However, several gaps in knowledge were identified by Shatkin and Kim (2015) when using life cycle assessment to identify and 
assess potential risks of cellulose nanomaterials from ocupational, consumer, and environmental exposures. Further studies are then required to focus on those gaps to ensure that any questions about cellulose materials safety are answered for safe and sustainable commercialization.

\section{Acknowledgements}

Authors thank the National Counsel of Technological and Scientific Development(CNPq, Brazil) for their financial support (402.287/2013-4, CNPq/SisNano) and for the Research Productivity Fellowships (304179/2012-4, 303796/2014-6, and 310368/2012-0, granted to authors Azeredo, Mattoso, and Rosa, respectively).

\section{References}

ASTM, 2000. Standard test method for tensile properties of thin plastic sheeting D882-00. In: Annual Book of ASTM Standards. American Society for Testing and Materials, Philadelphia, pp. 165-173.

Abdollahi, M., Alboofetileh, M., Behrooz, R., Rezaei, M., Miraki, R., 2013. Reducing water sensitivity of alginate bio-nanocomposite film using cellulose nanoparticles. Int. J. Biol. Macromol. 54, 166-173.

Alemdar, A., Sain, M., 2008. Biocomposites from wheat straw nanofibers: morphology: thermal and mechanical properties. Compos. Sci. Technol. 68, 557-565.

Anglès, M.N., Dufresne, A., 2000. Plasticized starch/tunicin whiskers nanocomposites. 1. Structural analysis. Macromolecules 33, 8344-8353.

Aulin, C., Gällstedt, M., Lindström, T., 2010. Oxygen and oil barrier properties of microfibrillated cellulose films and coatings. Cellulose 17, 559-574.

Azeredo, H.M.C., Mattoso, L.H.C., Wood, D., Williams, T.G., Avena-Bustillos, R.J., McHugh, T.H., 2009. Nanocomposite edible films from mango puree reinforced with cellulose nanofibers. J. Food Sci. 74, N31-N35.

Azeredo, H.M.C., Mattoso, L.H.C., Avena-Bustillos, R.J., Ceotto Filho, G., Munford, M.L., Wood, D., McHugh, T.H., 2010. Nanocellulose reinforced chitosan composite films as affected by nanofiller loading and plasticizer content. J Food Sci. 75, N1-N7

Azeredo, H.M.C., Miranda, K.W.E., Ribeiro, H.L., Rosa, M.F., Nascimento, D.M., 2012a. Nanoreinforced alginate-acerola puree coatings on acerola fruits. J. Food Eng. 113, 505-510.

Azeredo, H.M.C., Miranda, K.W.E., Rosa, M.F., Nascimento, D.M., De Moura, M.R., 2012b. Edible films from alginate-acerola puree reinforced with cellulose whiskers. LWT Food Sci. Technol. 46, 294-297.

Azeredo, H.M.C., 2013. Antimicrobial nanostructures in food packaging. Trends Food Sci. Technol. 30, 56-69.

BCC Research, 2013. BCC Research publishes a new report on global markets for biodegradable polymers, Available at http://www.bccresearch.com/ pressroom/pls/global-volume-biodegradable-polymers-market-reach-3billion-2019.

Barud, H.S., Souza, J.L., Santos, D.B., Crespi, M.S., Ribeiro, C.A., Messaddeq, Y., Ribeiro, S.J.L., 2011. Bacterial celulose/poly(3-hydroxybutyrate) composite membranes. Carbohydr. Polym. 83, 1279-1284.

Belbekhouche, S., Bras, J., Siqueira, G., Chappey, C., Lebrun, L., Khelifi, B., Marais, S. Dufresne, A., 2011. Water sorption behavior and gas barrier properties of celulose whiskers and microfibrils films. Carbohydr. Polym. 83, 1740-1748.

Bilbao-Sainz, C., Bras, J., Williams, T., Sénechal, T., Orts, W., 2011. HPMC reinforced with different cellulose nano-particles. Carbohydr. Polym. 86, 1549-1557.

Bondeson, D., Oksman, K., 2007. Dispersion and characteristics of surfactant modified cellulose whiskers nanocomposites. Compos. Interface 14, 617-630.

Chang, S.-T., Chen, L.-C., Lin, S.-B., Chen, H.-H., 2012. Nano-biomaterials application: Morphology and physical properties of bacterial cellulose/gelatin composites via crosslinking. Food Hydrocoll. 27, 137-144.

Chen, Y., Liu, C., Chang, P.R., Cao, X., Anderson, D.P., 2009. Bionanocomposites based on pea starch and cellulose nanowhiskers hydrolyzed from pea hull fibre: effect of hydrolysis time. Carbohydr. Polym. 76, 607-615.

Cho, M.-J., Park, B.-D., 2011. Tensile and thermal properties of nanocellulose-reinforced poly(vinyl alcohol) nanocomposites. J. Ind. Eng. Chem. 17, 36-40.

De Paula, E.L., Mano, V., Pereira, F.V., 2011. Influence of celulose nanowhiskers on the hydrolytic degradation behavior of poly(L-lactide). Polym. Degrad. Stab. 96 1631-1638.

Dhar, P., Bhardwaj, U., Kumar, A., Katiyar, V., 2015. Poly(3-hydroxybutyrate)/cellulose nanocrystal films for food packaging applications: barrier and migration studies. Polym. Eng. Sci. 55, 2388-2395.

Dong, H., Snyder, J.F., Tran, D.T., Leadore, J.L., 2013. Hydrogel: aerogel and Film of cellulose nanofibrils functionalized with silver nanoparticles. Carbohydr. Polym. 95, 760-767.

Duarte, E.B., Chagas, B.S., Andrade, F.K., Santa Brígida, A.I., Borges, M.F., Muniz, C.R., Souza Filho, M.S.M., Morais, J.P.S., Feitosa, J.P.A., Rosa, M.F., 2015. Production of hydroxyapatite-bacterial cellulose nanocomposites from agroindustrial wastes. Cellulose 22, 3177-3187.
Dufresne, A., Dupeyre, D., Vignon, M.R., 2000. Cellulose microfibrils from potato tuber cells: processing and characterization of starch-cellulose microfibril composites. J. Appl. Polym. Sci. 76, 2080-2092.

Dufresne, A., 2010. Processing of polymer nanocomposites reinforced with polysaccharide nanocrystals. Molecules 15, 4111-4128.

El-Wakil, N., Hassan, E.A., Abou-Zeid, R.E., Dufresne, A., 2015. Development of wheat gluten/nanocellulose/titanium dioxide nanocomposites for active food packaging. Carbohydr. Polym. 124, 337-346.

Favier, V., Canova, G.R., Cavaillé, J.Y., Chanzy, H., Dufresne, A., Gauthier, C., 1995 Nanocomposite materials from latex and cellulose whiskers. Polym. Adv. Technol. 6, 351-355.

Fernandes, S.C.M., Freire, C.S.R., Silvestre, A.J.D., Pascoal Neto, C., Gandini, A., Berglund, L.A., Salmén, L., 2010. Transparent chitosan films reinforced with a high content of nanofibrillated celulose. Carbohydr. Polym. 81, 394-401.

Follain, N., Belbekhouche, S., Bras, J., Siqueira, G., Marais, S., Dufresne, A., 2013. Water transport properties of bio-nanocomposites reinforced by Luffa cylindrica celulose nanocrystals. J. Membr. Sci. 427, 218-229.

Fortunati, E., Armentano, I., Zhou, Q., Iannoni, A., Saino, E., Visai, L., Berglund, L.A. Kenny, J.M., 2012a. Muntifunctional bionanocomposite films of poly(lactic acid): celulose nanocrystals and silver nanoparticles. Carbohydr. Polym. 87 1596-1605.

Fortunati, E., Peltzer, M., Armentano, I., Torre, L., Jiménez, A., Kenny, J.M., 2012b. Effects of modified cellulose nanocrystals on the barrier and migration properties of PLA nano-biocomposites. Carbohydr. Polym. 90, 948-956.

Fortunati, E., Luzi, F., Puglia, D., Dominici, F., Santulli, C., Kenny, J.M., Torre, L., 2014. Investigation of thermo-mechanical: chemical and degradative properties of PLA-limonene films reinforced with cellulose nanocrystals extracted from Phormium tenax leaves. Eur. Polym. J. 56, 77-91.

Gea, S., Bilotti, E., Reynolds, C.T., Soykeabkeaw, N., Peojs, T., 2010. Bacterial cellulose-poly(vinyl alcohol) nanocomposites prepared by an in-situ process. Mater. Lett. 64, 901-904.

George, J., Siddaramaiah, 2012. High performance edible nanocomposite films containing bacterial celulose nanocrystals. Carbohydr. Polym. 87, 2031-2037.

George, J., Ramana, K.V., Bawa, A.S., Siddaramaiah, 2011. Bacterial cellulose nanocrystals exhibiting high thermal stability and their polymer nanocomposites. Int. J. Biol. Macromol. 48, 50-57.

George, J., Kumar, R., Sajeevkumar, V.A., Ramana, K.V., Rajamanickam, R., Abhishek, V., Nadanasabapathy, S., Siddaramaiah, 2014. Hybrid HPMC nanocomposites containing bacterial celulose nanocrystals and silver nanoparticles. Carbohydr. Polym. 105, 285-292.

Grande, C.J., Torres, F.G., Gomez, C.M., Troncoso, O.P., Canet-Ferrer, J., Martínez-Pastor, J., 2009. Development of self-assembled bacterial cellulose-starch nanocomposites. Mater. Sci. Eng. C 29, 1098-1104

Huang, J.-Y., Li, X., Zhou, W., 2015. Safety assessment of nanocomposite for food packaging application. Trends Food Sci. Technol. 45, 187-199.

Hubbe, M.A., Rojas, O.J., Lucia, L.A., Sain, M., 2008. Cellulosic nanocomposites: a review. Bioresources 3, 929-980

Huq, T., Salmieri, S., Khan, A., Khan, R.A., Tien, C.L., Riedl, B., Fraschini, C., Bouchard, J., Eribe-Calderon, J., Kamal, M.R., Lacroix, M., 2012. Nanocrystalline cellulose (NCC) reinforced alginate based biodegradable nanocomposite film. Carbohydr. Polym. 90, 1757-1763.

Iwatake, A., Nogi, M., Yano, H., 2008. Cellulose nanofiber-reinforced polylactic acid Compos. Sci. Technol. 68, 2103-2106.

Jipa, I.M., Dobre, L., Stroescu, M., Stoica-Guzun, A., Jinga, S., Dobre, T., 2012a. Preparation and characterization of bacterial cellulose-poly(vinyl alcohol) films with antimicrobial properties. Mater. Lett. 66, 125-127.

Jipa, I.M., Stoica-Guzun, A., Stroescu, M., 2012b. Controlled release of sorbic acid from bacterial cellulose based mono and multilayer antimicrobial films. LWT Food Sci. Technol. 47, 400-406.

Jonoobi, M., Oladi, R., Davoudpour, Y., Oksman, K., Dufresne, A., Hamzeh, Y., Davoodi, R., 2015. Different preparation methods and properties of nanostructured cellulose from various natural resources and residues: a review. Cellulose 22, 935-969.

Khan, A., Khan, R.A., Salmieri, S., Le Tien, C., Riedl, B., Bouchard, J., Chauve, G., Tan, V., Kamal, M.R., Lacroix, M., 2012. Mechanical and barrier properties of nanocrystalline cellulose reinforced chitosan based nanocomposite films. Carbohydr. Polym. 90, 1601-1608.

Kim, Y.J., Lee, H.M., Park, O.O., 1995. Processabilities and mechanical properties of Surlyn-treated starch/LDPE blends. Polym. Eng. Sci. 35, 1652-1657.

Kim, Y.S., Song, M.Y., Park, J.D., Song, K.S., Ryu, H.R., Chung, Y.H., Chang, H.K., Lee, J.H., Oh, K.H., Kelman, B.J., Hwang, I.K., Yu, I.J., 2010. Subchronic oral toxicity of silver nanoparticles. Part. Fibre Toxicol. 7, 20 http://www. particleandfibretoxicology.com/content/pdf/1743-8977-7-20.pdf.

Kovacs, T., Naish, V., OConnor, B., Blaise, C., Gagné, F., Hall, L., Trudeau, V., Martel P., 2010. An ecotoxicological characterization of nanocrystalline cellulose (NCC). Nanotoxicology 4, 255-270.

Kumar, R., Münstedt, H., 2005. Silver ion release from antimicrobial polyamide/silver composites. Biomaterials 26, 2081-2088.

López-Rubio, A., Lagaron, J.M., Ankerfors, M., Lindström, T., Nordqvist, D., Mattozzi, A., Hedenqvist, M.S., 2007. Enhanced film forming and film properties of amylopectin using micro-fibrillated cellulose Carbohydr. Polym. 68, 718-727.

Lavoine, N., Desloges, I., Bras, J., 2014a. Microfibrillated cellulose coatings as new release systems for active packaging. Carbohydr. Polym. 103, 528-537.

Lavoine, N., Desloges, I., Khelifi, B., Bras, J., 2014b. Impact of different coating processes of microfibrillated cellulose on the mechanical and barrier properties of paper. J. Mater. Sci. 49, 2879-2893. 
Lavoine, N., Desloges, I., Sillard, C., Bras, J., 2014c. Controlled release and long-term antibacterial activity of chlorhexidine digluconate through the nanoporous network of microfibrillated cellulose. Cellulose 21, 4429-4442.

Lavoine, N., Givord, C., Tabary, N., Desloges, I., Martel, B., Bras, J., 2014d. Elaboration of a new antibacterial bio-nano-material for food packaging by synergistic action of cyclodextrin and microfibrillated cellulose. Innov. Food Sci. Emerg. Technol. 26, 330-340.

Lavoine, N., Tabary, N., Desloges, I., Martel, B., Bras, J., 2014e. Controlled release of chlorhexidine digluconate using $\beta$-cyclodextrin and microfibrillated cellulose. Colloids Surf. B Biointerfaces 121, 196-205.

Li, Q., Zhou, J., Zhang, L., 2009. Structure and properties of the nanocomposite films of chitosan reinforced with cellulose whiskers. J. Polym. Sci. 47, 1069-1077.

Li, F., Biagioni, P., Bollani, M., Maccagnan, A., Piergiovanni, L., 2013. Multi-functional coating of celulose nanocrystals for flexible packaging applications. Cellulose 20, 2491-2504

Lin, W.-C., Lien, C.-C., Yeh, H.-J., Yu, C.-M., Hsu, S.-H., 2013. Bacterial cellulose and bacterial cellulose-chitosan membranes for wound dressing applications. Carbohydr. Polym. 94, 603-611.

Ljungberg, N., Bonini, C., Bortolussi, F., Boisson, C., Heux, L., Cavaillé, J.Y., 2005. New nanocomposite materials reinforced with cellulose whiskers in atactic popypropylene: effect of surface and dispersion characteristics. Biomacromolecules 6, 2732-2739.

Martínez-Sanz, M., Abdelwahab, M.A., Lopez-Rubio, A., Lagaron, J.M., Chiellini, E., Williams, T.G., Wood, D.F., Orts, W.J., Imam, S.H., 2013a. Incorporation of poly(glycidylmethacrylate) grafted bacterial cellulose nanowhiskers in poly(lactic acid) nanocomposites: Improved barrier and mechanical properties. Eur. Polym. J. 49, 2062-2072.

Martínez-Sanz, M., Lopez-Rubio, A., Lagaron, J.M., 2013b. High-barrier coated bacterial celulose nanowhiskers films with reduced moisture sensitivity. Carbohydr. Polym. 98, 1072-1082.

Mathew, A.P., Dufresne, A., 2002. Morphological investigation of nanocomposites from sorbitol plasticized starch and tunicin whiskers. Biomacromolecules 3, 609-617.

Mesquita, J.P., Donnici, C.L., Teixeira, I.F., Pereira, F.V., 2012. Bio-based nanocomposites obtained through covalent linkage between chitosan and cellulose nanocrystals. Carbohydr. Polym. 90, 210-217.

Nguyen, V.T., Gidley, M.J., Dykes, G.A., 2008. Potential of a nisin-containing bacterial cellulose Film to inhibit Listeria monocytogenes on processed meats. Food Microbiol. 25, 471-478.

Ni, H., Zeng, S.Q., Wu, J., Cheng, X.R., Luo, T., Wang, W.Y., Zeng, W.J., Chen, Y., 2012. Cellulose nanowhiskers: preparation: characterization and cytotoxicity evaluation. Bio Med. Mater. Eng. 22, 121-127.

Oksman, K., Mathew, A.P., Bondeson, D., Kvien, I., 2006. Manufacturing process of cellulose whiskers/polylactic acid nanocomposites. Compos. Sci. Technol. 66, 2776-2784.

Paralikar, S.A., Simonsen, J., Lombardi, J., 2008. Poly(vinyl alcohol)/cellulose nanocrystal barrier membranes. J. Membr. Sci. 320, 248-258.

Pecoraro, E., Manzani, D., Messaddeq, Y., Ribeiro, S.J.L., 2008. Bacterial cellulose from Gluconacetobacter xylinus: preparation, properties and applications. In: Belgacem, M.N., Gandini, A. (Eds.), Monomers, Polymers and Composites from Renewable Resources. Elsevier, Oxford, pp. 369-383.
Peng, X.-w., Ren, J.-l., Zhong, L.-X., Sun, R.-c., 2011. Nanocomposite films based on xylan-rich hemicelluloses and cellulose nanofibers with enhanced mechanical properties. Biomacromolecules 2011, 3321-3329.

Pereda, M., Dufresne, A., Aranguren, M.I., Marcovich, N.E., 2014. Polyelectrolyte films based on chitosan/olive oil and reinforced with celulose nanocrystals. Carbohydr. Polym. 101, 1018-1026.

Petersson, L., Oksman, K., 2006. Biopolymer based nanocomposites: comparing layered silicates and microcrystalline cellulose as nanoreinforcement. Compos. Sci. Technol. 66, 2187-2196.

Petersson, L., Kvien, I., Oksman, K., 2007. Structure and thermal properties of poly(lactic acid)/cellulose whiskers nanocomposite materials. Compos. Sci. Technol. 67, 2535-2544.

Retegi, A., Gabilondo, N., Peña, C., Zuluaga, R., 2010. Bacterial cellulose films with controlled microstructure-mechanical property relationships. Cellulose 17, 661-669.

Salmieri, S., Islam, F., Khan, R.A., Hossain, F.M., Ibrahim, H.M.M., Miao, C., Hamad, W.Y., Lacroix, M., 2014. Antimicrobial nanocomposite films made of poly(lactic acid)-cellulose nanocrystals (PLA-CNC) in food applications: part A-effect of nisin release on the inactivation of Listeria monocytogenes in ham. Cellulose 21 1837-1850.

Sanchez-Garcia, M.D., Lagaron, J.M., 2010. On the use of plant cellulose nanowhiskers to enhance the barrier properties of polylactic acid. Cellulose 17, 987-1004.

Santos, T.M., Souza Filho, M.S.M., Caceres, C.A., Rosa, M.F., Morais, J.P.S., Pinto, A.M.B., Azeredo, H.M.C., 2014. Fish gelatin films as affected by cellulose whiskers and sonication. Food Hydrocoll. 41, 113-118.

Shatkin, J.A., Kim, B., 2015. Cellulose nanomaterials: life cycle risk assessment, and environmental health and safety roadmap. Environ. Sci. Nano 2, 477-499.

Soykeabkaew, N., Laosat, N., Ngaokla, A., Yodsuwan, N., Tunkasiri, T., 2012. Reinforcing potential of micro- and nano-sized fibers in the starch-based biocomposites. Compos. Sci. Technol. 72, 845-852.

Tomé, L.C., Brandão, L., Mendes, A.M., Silvestre, A.J.D., Pascoal Neto, C., Gandini, A., Freire, C.S.R., Marrucho, I.M., 2010. Preparation and characterization of bacterial celulose membranes with tailored surface and barrier properties. Cellulose 17, 1203-1211.

Ul-Islam, M., Khan, T., Park, J.K., 2012. Nanoreinforced bacterial cellulose-montmorillonite composites for biomedical applications. Carbohydr. Polym. 89, 1189-1197.

Wang, Y., Cao, X., Zhang, L., 2006. Effects of cellulose whiskers on properties of soy protein thermoplastics. Macromol. Biosci. 6, 524-531.

Wang, B., Sain, M., Oksman, K., 2007. Study of structural morphology of hemp fiber from the micro to the nanoscale. Appl. Compos. Mater. 14, 89-103.

Xiu, Z., Zhang, Q., Puppala, H.L., Colvin, V.L., Alvarez, P.J.J., 2012. Negligible particle-specific antibacterial activity of silver nanoparticles. Nano Lett. 12 4271-4275.

Xu, X., Liu, F., Jiang, L., Zhu, J.Y., Haagenson, D., Wiesenborn, D.P., 2013. Cellulose nanocrystals vs. cellulose nanofibrils: a comparative study on their microstructures and effects as polymer reinforcing agents. ACS Appl. Mater. Interfaces 5, 2999-3009.

Zhu, H., Jia, S., Yang, H., Tang, W., Jia, Y., Tan, Z., 2010. Characterization of bacteriostatic sausage casing: A composite of bacterial cellulose embedded with $\varepsilon$-polylysine. Food Sci. Biotechnol. 19, 1479-1484. 